\title{
Increased blood pressure in schoolchildren related to high sodium levels in drinking water
}

\author{
A. HOFMAN AND H. A. VALKENBURG \\ From the Department of Epidemiology, Erasmus University, Rotterdam \\ G. J. VAANDRAGER \\ From the Netherlands Institute of Preventive Medicine, Leiden
}

SUMMARY The relationship between sodium in drinking water and blood pressure was examined in 348 schoolchildren aged 7.7 to 11.7 years. They were born and living in three areas with different levels of sodium in the public drinking water. Sodium content of the water was either long-term low, long-term high, or short-term high. The three communities are closely comparable according to demographic characteristics. The mean values of systolic and diastolic blood pressure were higher in the high sodium areas. After adjustment for dissimilarities in distributions of weight, height, pulse rate, age, family history of hypertension, and time of blood pressure measurement, these differences remained constant, ranging from 1.8 to $4.0 \mathrm{~mm} \mathrm{Hg}$. Girls and boys showed essentially the same differences. Mean 24-hour sodium excretion was somewhat higher in the long-term low area; no differences were found in sodium-creatinine ratio. The regression coefficients between sodium excretion and blood pressure were not significant. The findings from this retrospective follow-up study support the hypothesis that sodium intake influences blood pressure. The association seems to be of a relatively short-term nature, as no differences in blood pressure levels were found between the long-term and short-term high areas.

The role of high sodium intake in the pathogenesis of essential hypertension has been emphasised for a long time. ${ }^{1}$ Epidemiologically this is mainly based on comparisons of the mean blood pressure levels of different populations with varying sodium intakes. Within populations, however, the results of blood pressure studies have been equivocal. ${ }^{2-6}$ Most of these investigations were cross-sectional, relating a casual blood pressure reading to an estimate of sodium intake at the same time. The major problems of this approach are that the estimates of sodium intake are generally very crude; furthermore, the time-course of the relation between dietary sodium and blood pressure is not taken into account. Therefore, follow-up studies are preferable because these can provide insight into the temporal aspects of the relationship under study.

Calabrese $e t a^{7}$ reported elevated blood pressure levels in adolescents living in a community with a high sodium content in the drinking water. In this paper data are presented from a retrospective follow-up study of blood pressure in Dutch schoolchildren living in areas with markedly different levels of sodium in the drinking water.

\section{Material and methods}

Blood pressure was measured in 348 children, born and still living in three rural Dutch communities. The areas with long-term low and long-term high sodium levels had experienced only minor changes in the drinking water content over the past 15 years. About one year before the study, the sodium levels in the short-term high community changed from approximately 1 to $7 \mathrm{mmol} / \mathrm{l}$ because of the introduction of $\mathrm{NaOH}$ as an ion-exchanger to soften the water.

The three areas are closely comparable according to demographic characteristics and no significant differences were found in the occupations of parents of the study children.

All children born between 1968 and 1971 and attending the eight largest primary schools in the areas were asked to participate. The response rate was $98 \%$ and the age of the children varied from 7.7 to 11.7 years.

Blood pressure was measured with a random-zero sphygmomanometer to reduce observer bias. ${ }^{8}$ The readings were made by one observer, who was not aware of the sodium content of the drinking water. Blood pressure was measured in duplicate and the two readings were separated in time only by measurement of the heart rate. All subjects were studied within a two-week period in September 1979. Blood pressure was taken after at least five minutes of rest on the left arm of the sitting subject. Korotkoff sound $\mathrm{V}$ was taken as diastolic blood pressure and the 
mean of the duplicate readings was used in the analysis.

Weight, height, and pulse rate were recorded. Sodium intake was estimated by measuring urinary sodium excretion. Sodium and potassium concentrations in a 24-hour urine sample were measured by flame-photometry. Urinary creatinine concentration was measured by an automated enzymatic method (Technicon). Only children exceeding an excretion of $0.16 \mathrm{mmol}$ creatinine/24 $\mathrm{hrs} / \mathrm{kg}$ body weight were taken into the analysis. A family history of hypertension was assessed by asking the parents whether they or the child's grandparents had ever received any anti-hypertensive medication.

\section{Results}

Mean blood pressure values were higher in the areas with high sodium levels in the drinking water (Table 1). These differences could have been due to unlike distributions of the determinants of blood pressure in the study communities, so adjustment was made for variables known to be determinants of blood pressure in childhood. ${ }^{9}$ In a model for multiple linear regression the effect of residence on systolic and diastolic blood pressure was calculated, and adjustment was made for weight, height, pulse rate, age, family history of hypertension, and time of blood pressure measurement.

Table 1 Mean blood pressure $( \pm S D)$ values in three areas with different sodium levels in the drinking water

\begin{tabular}{lccc}
\hline & $\begin{array}{l}\text { Long-term } \\
\text { low }\end{array}$ & $\begin{array}{l}\text { Short-term } \\
\text { high }\end{array}$ & $\begin{array}{l}\text { Long-term } \\
\text { high }\end{array}$ \\
\hline Systolic BP (mm Hg) & $100 \cdot 2 \pm 12 \cdot 3$ & $103 \cdot 4 \pm 9 \cdot 7$ & $102 \cdot 9 \pm 10 \cdot 9$ \\
Diastolic BP (mm Hg) & $57 \cdot 4 \pm 8 \cdot 6$ & $59 \cdot 3 \pm 9 \cdot 4$ & $59 \cdot 5 \pm 7 \cdot 8$ \\
Weight (kg) & $33 \cdot 5 \pm 6 \cdot 7$ & $32 \cdot 0 \pm 6 \cdot 4$ & $32 \cdot 1 \pm 6 \cdot 2$ \\
Height (cm) & $143 \pm 9$ & $141 \pm 10$ & $141 \pm 9$ \\
Age (years) & $10 \cdot 0 \pm 1 \cdot 2$ & $9 \cdot 6 \pm 1 \cdot 2$ & $9 \cdot 7 \pm 1 \cdot 2$ \\
No. & 110 & 112 & 126 \\
\hline
\end{tabular}

Table 2 shows the differences between the mean values of systolic and diastolic blood pressure in high vs low sodium areas, before and after adjustment. All differences were statistically significant and ranged from 1.8 to $4.0 \mathrm{~mm} \mathrm{Hg}$.

No significant differences were found in mean blood pressure between children living in the long-term high and the short-term high areas. Girls and boys showed essentially the same adjusted effect of residence on systolic and diastolic blood pressure.

Mean values of 24-hour excretion of urinary sodium, potassium and creatinine are given in Table 3. The sodium excretion in 24 hours was larger in the long-term low area; no differences in potassium excretion were found. Mean creatinine excretion was
Table 2 Differences between mean blood pressure values in $\mathrm{mm} \mathrm{Hg:} \mathrm{long-term} \mathrm{high} \mathrm{vs} \mathrm{long-term} \mathrm{low} \mathrm{area,} \mathrm{and} \mathrm{short-}$ term high vs long-term low area

\begin{tabular}{lll}
\hline & \multicolumn{2}{l}{ Long-term high minus long-term low } \\
\cline { 2 - 3 } & Observed & Adjusted $\dagger$ \\
\hline Systolic BP & $2 \cdot 7^{*}$ & $3 \cdot 3^{* * *}$ \\
Diastolic BP & $2 \cdot 1^{* *}$ & $1 \cdot 8^{*}$ \\
& Short-term high minus long-term low \\
\cline { 2 - 3 } & Observed & Adjusted $\dagger$ \\
\hline Systolic BP & $3 \cdot 2^{* *}$ & $4 \cdot 0^{* * *}$ \\
Diastolic BP & $1 \cdot 9^{*}$ & $2 \cdot 3^{* *}$ \\
\hline
\end{tabular}

$\uparrow$ Adjusted for weight, height, pulse rate, family history of hypertension, time of blood pressure measurement.

$* \mathrm{P}<0.10$

$* * \mathrm{P}<0.05$

$* * * P<0.01$ (two-sided t-test)

larger in the long-term low area, but no significant differences in sodium-creatinine ratio were found between the communities. Adjustment for body weight and age slightly diminished the differences in sodium excretion between the areas. The standardised regression coefficients between urinary $\vec{v} \vec{v}$ sodium excretion and systolic $(b=0.02)$ and 0 diastolic $(b=0.01)$ blood pressure were non-significant.

Table 3 Mean values of electrolytes and creatinine in 24-hour urine sample in three areas with different sodium levels in the drinking water

\begin{tabular}{lcccc}
\hline & $\begin{array}{l}\text { Long-term } \\
\text { low }\end{array}$ & $\begin{array}{l}\text { Short-term } \\
\text { high }\end{array}$ & $\begin{array}{l}\text { Long-term } \\
\text { high }\end{array}$ \\
\hline $\mathrm{Na}^{+}$(mmol/24 hrs) & $109 \pm 40$ & $88 \pm 39$ & $98 \pm 39$ \\
$\mathrm{~K}^{+}$(mmol/24 hrs) & $43 \pm 15$ & $37 \pm 23$ & $42 \pm 17$ \\
$\mathrm{Creatinine}(\mathrm{mmol} / 24 \mathrm{hrs})$ & $7 \cdot 9 \pm 1 \cdot 8$ & $6 \cdot 2 \pm 2 \cdot 0$ & $7 \cdot 1 \pm 1 \cdot 7$ \\
$\mathrm{Na}$ /creatinine ratio & 14 & 14 & 14 \\
$\mathrm{~N}$ & 107 & 104 & 123 \\
\hline
\end{tabular}

\section{Discussion}

Our finding that blood pressure levels are higher in high sodium areas agrees with that of Calabrese et al. ${ }^{7}$ However, there are three differences between our study and theirs.

In the American study no device was used to reduce observer bias in the measurement of blood pressure. If the observers were aware of the hypothesis the results could have been seriously distorted. Furthermore, the previous study considered blood pressure levels only in long-term high and low communities. Finally, Calabrese et al $^{10}$ found higher mean levels of excreted sodium in the 
high sodium areas, but in our study the sodium excretion was somewhat larger in the low sodium community.

In the first period of life a child gets a relatively large part of his or her dietary sodium from water, at least when living in a high sodium region and receiving artificial feeding. As most Dutch formula feedings contain 10-20 mmol Na${ }^{+} / 1$, the infant fed solely on the bottle in a high sodium area $(5-10 \mathrm{mmol}$ $\mathrm{Na}^{+} / 1$ ) obtains about $20-50 \%$ of its sodium from the water, compared with $5 \%$ in a low sodium community. However, this cannot explain our finding of similar blood pressure levels in the short-term high and the long-term high areas.

The collection of data on total intake of sodium is fraught with problems. Urinary sodium excretion was used as an indicator of total sodium intake. We considered direct estimation of sodium intake to be impossible, because of the crudeness of dietary recall and duplicate portion methods. We found no differences in sodium-creatinine ratio in the 24-hour urine. Unfortunately, the marked intra-individual variability of sodium intake implies that one 24-hour urine collection is not enough to estimate the relationship between sodium intake and blood pressure. ${ }^{11}$ A considerable number of 24-hour urine collections is necessary to assess the true value of the association. ${ }^{12}$ This would involve large practical problems in general population studies and emphasises the need for follow-up studies in this field, especially of the prospective type.

Nevertheless, the findings from this retrospective follow-up study support the hypothesis that blood pressure is related to sodium intake. The association seems to be of a relatively short-term nature: in the community with a recent change to high sodium levels the effect was discernible after one year. Evidence exists for early 'tracking' of blood pressure, ${ }^{13}$ perhaps even from the first months of life,,$^{14}$ so this could indicate that sodium intake is an important early determinant of 'tracking'. It may well be that genetic predisposition to high blood pressure expresses itself through environmental factors, especially high sodium intake, as early as the first period of life.

We thank the children who participated in the study, and Mrs. Wilma Haanen, Mrs. Ria Rijneveldshoek, Mr. Bram van Laar, Mr. A. M. de Brūyn, Dr. M. M. Dieleman, Dr. N. C. Lamaison van den Berg, and Dr.
R. Bloembergen. We also thank Mr. W. Bassie of the WMZ Water Works. This study was supported in part by the Netherlands Prevention Fund.

Reprints from Dr. A. Hofman, Department of Epidemiology, Erasmus University, PO Box 1738, 3000 DR Rotterdam, The Netherlands.

\section{References}

${ }^{1}$ Ambard L, Beaujard E. Causes de l'hypertension arterielle. Arch Gen Med 1904; 1: 520-34.

${ }^{2}$ Dawber TR, Kannel WB, Kagan A, Donabedian RK, McNamara PM, Pearson G. In: Stamler J, Stamler R, Pullman TA, ed. The Epidemiology of Hypertension. New York: Grune and Stratton, 1967: 255-83.

${ }^{3}$ Langford HG, Watson RL, Douglas BH. Factors affecting blood pressure in population groups. Trans Assoc Am Physicians 1968; 81: 135-46.

${ }^{4}$ Parijs J, Joossens JV, Van der Linden L, Verstreken G, Amery AKPC. Moderate sodium restriction and diuretics in the treatment of hypertension. Am Heart $J$ 1973; 85: 22-34.

${ }^{5}$ Morgan T, Carney S, Wilson M. Interrelationship in humans between sodium intake and hypertension. Clin. Exp Pharmacol Physiol 1975; 2, suppl: 127-9.

${ }^{6}$ Doyle AE, Chua KG, Duffy $S$. Urinary sodium, potassium and creatinine excretion in hypertensive and normotensive Australians. Med J Aust 1976; ii: 898-900.

${ }^{7}$ Calabrese EJ, Tuthill RW. Elevated blood pressure and high sodium levels in the public drinking water. Arch Environ Health 1977; 35: 200-2.

${ }^{8}$ Wright BM, Dore CF. A random-zero sphygmomanometer. Lancet 1970; ii: 337-8.

${ }^{9}$ Hofman A, Valkenburg HA. In: Joossens JV, Kesteloot $\mathrm{H}$, ed. The Epidemiology of Arterial Hypertension. The Hague: Martinus Nijhoff (in press).

${ }^{10}$ Calabrese EJ, Tuthill RW, Klar JM, Sieger TL. Elevated levels of sodium in community drinking water: a possible cause of increased blood pressure in elementary and high school students-results of epidemiological investigations. Paper presented at American Water Works Conference, June 1979, San Francisco, USA.

${ }^{11}$ Liu K, Stamler J, Dyer A, McKeever J, McKeever P. Statistical methods to assess and minimize the role of intra-individual variability in obscuring the relationship between dietary lipids and serum cholesterol. J Chronic Dis 1978; 31: 399-418.

${ }^{12}$ Liu K, Cooper T, McKeever J, Assessment of the association between habitual salt intake and high blood pressure. Am J Epidemiol 1979; 110: 219-26.

${ }^{13}$ Zinner SH, Martin LF, Sacks F. Rosner B, Kass EH. A longitudinal study of blood pressure in childhood. Am J Epidemiol 1974; 100: 437-42.

${ }^{14}$ De Swiet M, Fayers P, Shinebourne EA. Blood pressure survey in a population of newborn infants. $\mathrm{Br}$ Med $J$ 1976; ii: 9-11. 